\title{
Statistics of lower tropospheric inversions over the continental United States
}

\author{
Y. H. Zhang ${ }^{1, *, * *}$, S. D. Zhang ${ }^{1, *, * *}$, F. Yi ${ }^{1, *, * *}$, and Z. Y. Chen ${ }^{2}$ \\ ${ }^{1}$ School of Electronic Information, Wuhan University, Wuhan, Hubei, China \\ ${ }^{2}$ Institute of Atmospheric Sciences, Chinese Academy of Sciences, Beijing, China \\ *also at: Key Laboratory of Geospace Environment and Geodesy, Ministry of Education, Wuhan, Hubei, China \\ **also at: State Observatory for Atmospheric Remote Sensing, Wuhan, China
}

Received: 2 December 2009 - Revised: 25 January 2011 - Accepted: 27 January 2011 - Published: 22 February 2011

\begin{abstract}
The basic structure parameters of lower tropospheric inversions (LTIs) have been derived from 10 years (1998-2007) of high vertical resolution $(\sim 50 \mathrm{~m})$ radiosonde observations over 56 United States stations. Seasonal and longitudinal variability of these parameters are presented and the formation mechanisms of LTI are also discussed. It is found that LTI seems to be a common feature over the continental United States. The LTI occurrence rates (defined as the fraction of measurements with LTI, which is calculated from the number of LTI cases divided by the number of measurements of the whole 10 years) at these 56 stations vary from $3.7 \%$ to $14.5 \%$; the averaged base heights of LTI have a range of 3-5 km above mean sea level (a.m.s.l.); the averaged thicknesses and temperature jump ranges from 420-465 m and 1.9-2.2 K, respectively. These parameters have an obvious seasonal variation. In winter, all the occurrence rates, thicknesses and temperature jumps of LTI have much larger values than those in summer. LTI occurrence rate shows an obvious west-east increasing trend in all 4 seasons. Detailed analyses reveal that dynamical instability induced by strong zonal wind shear is responsible for LTI in winter, spring and autumn; the frontal system tends to generate LTI in summer. Since the higher occurrence rate, larger temperature jump and larger thickness of LTI occur in winter, we believe strong zonal wind shear plays a more important role in the formation of LTI.
\end{abstract}

Keywords. Atmospheric composition and structure (Pressure, density and temperature) - Meteorology and atmospheric dynamics (Climatology; Mesoscale meteorology)

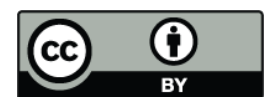

Correspondence to: S. D. Zhang (zsd@whu.edu.cn)

\section{Introduction}

Generally, in the troposphere, the atmospheric temperature decreases with increasing height in a quite uniform manner; an inversion layer is the layer where the temperature increases with height; the base of the inversion is the lowest altitude at which the temperature increases (Glickman, 2000). The inversion layer will influence local atmospheric thermal and dynamical structure. For example, the inversion layer can inhibit vertical mixing and dissipation (Palmén and Newton, 1969; Thomas, 1987; Johnson et al., 1999) and it acts as a lid to oppose strong convection (Nodzu et al., 2006) and influences cloud formation (Johnson et al., 1999).

A lower tropospheric inversion (LTI) here refers to the inversion layer usually existing in the lower troposphere (2$7 \mathrm{~km}$ ). It is distinguished from a boundary inversion layer and upper tropospheric inversion layer. The boundary inversion layer is often observed in the boundary layer, below $2 \mathrm{~km}$ (Busch et al., 1982). This inversion layer, therefore, acts as a lid or barrier in regard to near-surface and atmosphere constituent exchange. The upper-tropospheric inversion (UTI), firstly reported by Fujiwara et al. (2003), which is produced and maintained by strong longwave cooling in the wet layer, seems to be a common feature of the tropical upper troposphere. The height where LTI exists, usually ranged from 3 to $4 \mathrm{~km}$, is between the height of boundary inversion layer and UTI. However, there also exists another inversion in the lower troposphere, named trade wind inversion (TWI). Different from LTI, TWI is prevalent at in an altitude of about $2 \mathrm{~km}$ in a trade-wind belt, especially over the Hawaiian Islands, the Pacific and the Atlantic (Paul, 1968; Augstein et al., 1974; Hashizume et al., 2002). The mechanisms of TWI in different regions are generally different (Chen, 2006; Zhang et al., 2007). Nodzu et al. (2006) found that the inversion layers (stable layers) frequently appeared

Published by Copernicus Publications on behalf of the European Geosciences Union. 
in lower-troposphere over the Indochina Peninsula region $\left(1^{\circ} \mathrm{N}-25^{\circ} \mathrm{N}\right)$ during boreal winter and gave seasonal, vertical and geographical variations of the stable layer frequency.

At present, it has been recognized that lower tropospheric inversions have a close relationship with local meteorological and dynamical features in the lower troposphere, such as, relative humidity, cloud, precipitation, wind shear, etc. (Thomas, 1987; Kahl et al., 1992). However, the exact mechanism of LTI is still unclear. By analysing intensive radiosonde observations in January 2007 on an eight-timesdaily basis, Zhang et al. (2009) studied two lower tropospheric inversion events over Yichang $\left(111^{\circ} 18^{\prime} \mathrm{E}, 30^{\circ} 42^{\prime} \mathrm{N}\right)$ and discussed their formation mechanisms. They found that these two inversions significantly impacted on the stratification of the local atmosphere and their formation mechanisms were closely related to intensive inertial gravity waves, strong wind shear and local turbulence. Gravity wave induced intensive turbulence via convective instability may yield a downward energy transport and finally form the LTI.

Many previous works (Keyser and Shapiro, 1986; Nielsen and Neilley, 1990) indicated that the frontal system may also cause the inversion layers in the lower troposphere. A front in meteorology is defined as the interface or transition zone between two air masses of different density. Since temperature distribution is the most important regulator of atmospheric density, a front almost invariably separates air masses of different temperature (Glickman, 2000). These two air masses with different temperature may encounter each other due to the horizontal wind. At this time, the warmer air ascends due to its smaller density and lower pressure while the cold air descends due to its larger density and higher pressure. Then, it usually forms an apparent inversion structure. Nevertheless,researches on LTIs are generally sparse, especially the statistical work, including seasonal and geographical variability of the basic structure parameters of LTIs. Therefore, the statistical work of LTIs is of significant importance.

Radiosonde soundings have been extensively applied to study the tropospheric inversions (Fujiwara et al., 2003; Birner et al., 2006; Nodzu et al., 2006; Zhang et al., 2009). Radiosonde observations made by meteorology stations have been conducted routinely for decades in many stations around the world. Routine radiosonde observations on a twice daily basis have broad geographical coverage, long term accumulation and simultaneous measurements of wind, temperature and relative humidity with high vertical resolution, which allows us to study the statistical characteristics (including seasonal, annual and geographical variability) of the basic structure parameters of LTIs.

Several recent studies have examined the tropospheric inversions characteristics using satellite observations (Liu and Key, 2003; Kay and Gettelman, 2009). Satellite data, such as, Moderate Resolution Imaging Spectroradiometer (MODIS) data and Atmospheric Infrared Sounder (AIRS) data, have high spatial and temporal resolutions. However, they have limitations on detailed examination of inversions. For ex- ample, MODIS data are limited to clear-sky conditions and most satellite data have limited vertical resolution. Here, we use the full vertical resolution of radiosonde observations to define more precisely the inversion layer.

In the present paper, we statistically study the basic properties (including seasonal, annual, inter-annual and geographical variability) of LTI by analysing data from 56 radiosonde stations over the continental United States in the period of 1998-2007. Based on these statistical results, we investigate possible formation mechanisms of LTIs. The rest of the paper is organized as follows. Section 2 describes dataset utilized in this paper. Section 3 shows statistical results of the properties of LTIs and discuss the formation mechanisms of LTI. The primary conclusions are given in the last section.

\section{Data and methods}

The data used in this paper are the United States radiosonde data in 1998-2007 obtained from National Oceanic and Atmospheric Administration (NOAA) National Climatic Data Centre (NCDC). These data are freely accessed through the Stratospheric Processes and Their Role in Climate (SPARC) Data Center (http://www.sparc.sunysb.edu/). There are 93 stations in total, located across the contiguous United States, Alaska, Hawaii, Caribbean islands and the western tropical Pacific islands. Considering we focus on LTI in this paper, we should avoid the TWI regions, such as, the coastlands in the trade-wind belt. And having analysed the data from high latitude stations in the latitude range of $\left(55^{\circ} \mathrm{N}, 71.3^{\circ} \mathrm{N}\right)$, we found that the boundary inversion layer is ubiquitous but LTI is rare. The LTI occurrence rate (defined as the fraction of measurements with LTI, which is calculated from the number of LTI cases divided by the number of measurements in the whole 10 years) in this latitudinal region, has never exceeded $10 \%$. Hence, in this paper, the data from the coastlands in the trade-wind belt and the high latitude stations are excluded from our dataset. And, only the data from 56 mid-latitude stations are adopted. Figure 1 illustrates the geographical locations of these 56 stations. The longitudinal and latitudinal coverage of these 56 stations are $\left(68^{\circ} \mathrm{W}, 124.6^{\circ} \mathrm{W}\right)$ and $\left(31.9^{\circ} \mathrm{N}, 48.5^{\circ} \mathrm{N}\right)$, respectively.

Generally, at each station, radiosonde observations are launched twice daily at 00:00 and 12:00 UT. In each measurement by radiosonde, meteorological variables such as pressure, temperature and relative humidity are measured. The horizontal winds can be attained by tracking the position of the balloon. The measurement is sampled at a 6-s interval, resulting in an uneven height resolution of about $30 \mathrm{~m}$. For convenience, in this paper raw data were processed to have an even height resolution (i.e., $\Delta z=50 \mathrm{~m}$ ) by applying a linear interpolation to temperature and pressure data and a cubicspline interpolation to wind measurements. Since the averaged thickness of LTI is about $500 \mathrm{~m}$, it is reasonable to set the height resolution to be $50 \mathrm{~m}$. 


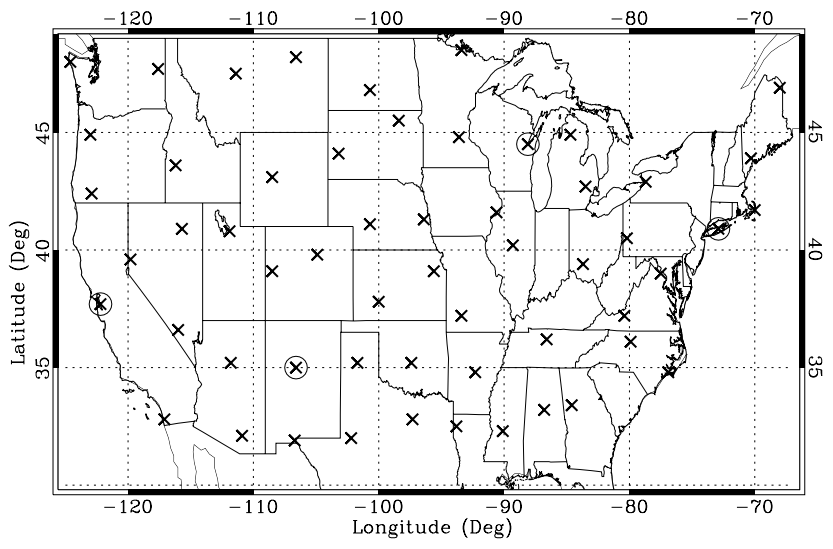

Fig. 1. Geographical locations of 56 Radiosonde stations used in this study. The stations with circles denote the positions of the stations used in the case study. The stations are Oakland International Airport $\left(37.7^{\circ} \mathrm{N}, 122.2^{\circ} \mathrm{W}\right)$, Albuquerque $\left(35^{\circ} \mathrm{N}, 106.6^{\circ} \mathrm{W}\right)$, Green Bay $\left(44.5^{\circ} \mathrm{N}, 88.1^{\circ} \mathrm{W}\right)$ and Brookhaven $\left(40.9^{\circ} \mathrm{N}, 72.9^{\circ} \mathrm{W}\right)$, respectively.

As that adopted by Zhang et al. (2009), we use the temperature jump $(\Delta T)$ as the criterion of the inversion. When $\Delta T>1 \mathrm{~K}$, an inversion layer is identified. We also examined the situation when $\Delta T>1.5 \mathrm{~K}$ and $\Delta T>2 \mathrm{~K}$. It was found that the major trend of tropospheric inversion parameters remained the same. We define the height difference of the temperature increasing region as the thickness of the inversion layer; the height where temperature begins to increase with the altitude is the inversion occurrence height, i.e., the base of the inversion. As LTI is a free-tropospheric phenomenon, the base of LTI here is the height above mean sea level (a.m.s.l.).

Figure 2 illustrates a temperature-height profile and the details of LTI case over Brookhaven, New York $\left(40.9^{\circ} \mathrm{N}\right.$, $72.9^{\circ} \mathrm{W}$ ) station at 12:00 UT on 15 November 2003. Two horizontal dashed lines denote heights of 2 and $7 \mathrm{~km}$. It exhibits various inversion structures at different heights. In the boundary layer below $2 \mathrm{~km}$, there is a boundary inversion layer at about $1 \mathrm{~km}$; at the height of about $11 \mathrm{~km}$, there exists another kind of inversion called the first tropopause or the extratropical tropopause (Hoinka, 1999), which is a permanent feature at mid-latitude regions. Between 2 and $7 \mathrm{~km}$, there also exists an inversion structure, which is the LTI studied in this paper. Therefore, we focus on the height range of $2-$ $7 \mathrm{~km}$ above ground level ( $\mathrm{km}$ a.g.l.) in this paper to avoid the boundary inversion layer and the first tropopause. It is noteworthy that the atmospheric boundary layer occurs generally in the range of about $1-1.5 \mathrm{~km}$ a.g.l. Hence, the "height" in the following context refers to the height above ground level (a.g.1.). However, the first tropopause is usually defined as the height a.m.s.l.. Therefore, the upper boundary of the LTI $(7 \mathrm{~km})$ in our study is the height a.m.s.l. According to the right panel of Fig. 2, it is also observed that the base height of the LTI, where temperature starts to increase, is at about
$4.1 \mathrm{~km}$; the temperature jump of the LTI, i.e., the amplitude of increasing temperature, is approximately $3 \mathrm{~K}$; the thickness of the LTI, which is the height range of increasing temperature, is around $600 \mathrm{~m}$.

\section{Results}

\subsection{Case study}

In this section, we first give the detailed vertical structure near LTI found in Fig. 2 and then give results about the structure parameters of LTI throughout the whole 10 years over 4 stations in different longitudes, which are Oakland International Airport, California $\left(37.7^{\circ} \mathrm{N}, 122.2^{\circ} \mathrm{W}\right)$, Albuquerque, New Mexico $\left(35^{\circ} \mathrm{N}, 106.6^{\circ} \mathrm{W}\right)$, Green Bay, Wisconsin $\left(44.5^{\circ} \mathrm{N}, 88.1^{\circ} \mathrm{W}\right)$ and Brookhaven, New York $\left(40.9^{\circ} \mathrm{N}, 72.9^{\circ} \mathrm{W}\right)$. The elevations of these 4 stations are 6 , 1615, 214 and $20 \mathrm{~m}$. The circles in Fig. 1 denote the position of these 4 stations.

Figure 3 shows the profiles of temperature, horizontal wind $\left(\sqrt{u^{2}+v^{2}}\right)$, buoyancy frequency square $\left(N^{2}\right)$, horizontal wind shear $\left(S^{2}=\left(\frac{\Delta u}{\Delta z}\right)^{2}+\left(\frac{\Delta v}{\Delta z}\right)^{2}\right.$, where $\Delta u$ and $\Delta v$ are zonal and meridional wind differences between two adjacent heights, respectively) and Richardson number $\left(R i=\frac{N^{2}}{S^{2}}\right)$ over Brookhaven $\left(40.9^{\circ} \mathrm{N}, 72.9^{\circ} \mathrm{W}\right)$ at $12: 00 \mathrm{UT}$ on 15 November 2003. Obviously different stratification characteristics between the atmosphere above and below the inversion layer can be observed from Fig. 3. The LTI indeed enhances the static stability around it. For instance, $N^{2}$ inside the inversion layer has a maximum value of $8.3 \times 10^{-4} \mathrm{~s}^{-2}$, which is at least twice greater than that outside the inversion. The horizontal wind shear begins to increase from $\sim 200 \mathrm{~m}$ under the base of the LTI and has a local maximum $\left(13.2 \times 10^{-6} \mathrm{~s}^{-2}\right)$ just at the base of the LTI. As to the Richardson number at $\sim 1 \mathrm{~km}$ above the top inversion layer, it is quite smaller than the one below the inversion layer, indicating an unstable atmospheric structure above the LTI. Generally, these results indicate that there may be a close relationship between the LTI and the enhanced horizontal wind shear.

Figure 4 displays the time series of monthly occurrence rate of LTI (thin red curve) and mean horizontal wind shear averaged over the height coverage from 2 to $5 \mathrm{~km}$ (thick curve) over 4 stations in 1998-2007. The averaged occurrence rates in the whole 10 years over these 4 stations are $5.8 \%, 5.2 \%, 9.8 \%$ and $13.8 \%$. The stations located in the west have much smaller occurrence rates than those located in the east. Monthly variations of the occurrence rates at all 4 stations are quite similar to those of the mean horizontal wind shear. We individually calculate the correlation coefficient between the monthly occurrence rates of LTI and the mean horizontal wind shear for these 4 stations. The correlation coefficients of Oakland International Airport $\left(37.7^{\circ} \mathrm{N}, 122.2^{\circ} \mathrm{W}\right)$, Albuquerque $\left(35^{\circ} \mathrm{N}, 106.6^{\circ} \mathrm{W}\right)$, Green 

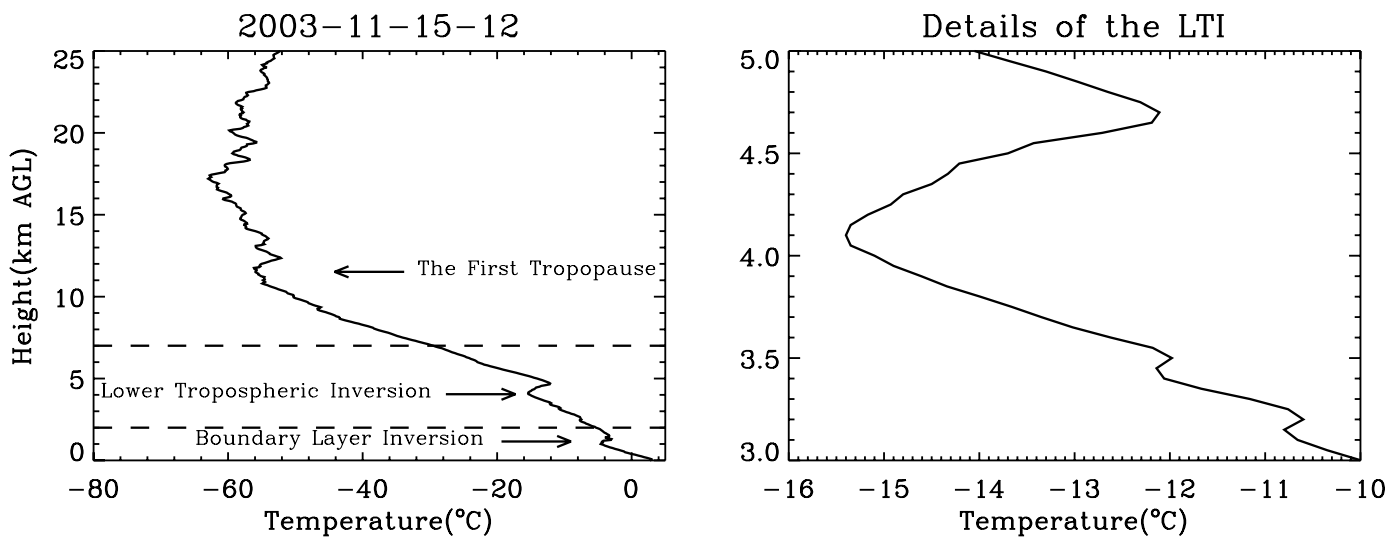

Fig. 2. Temperature-height profile over Brookhaven $\left(40.9^{\circ} \mathrm{N}, 72.9^{\circ} \mathrm{W}\right)$ at 12:00 UT on 15 November 2003.

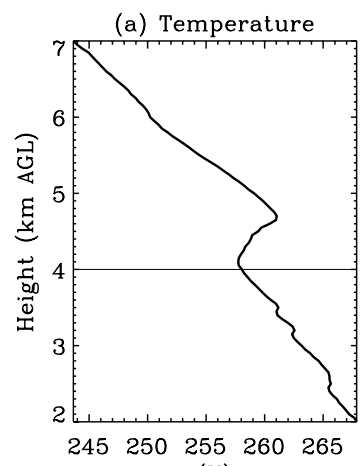

(K) (b) Horizontal Wind

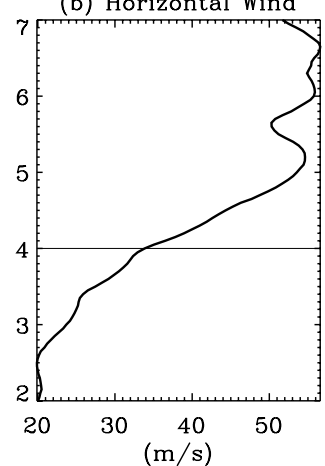

(c) $\mathrm{N}^{2}$

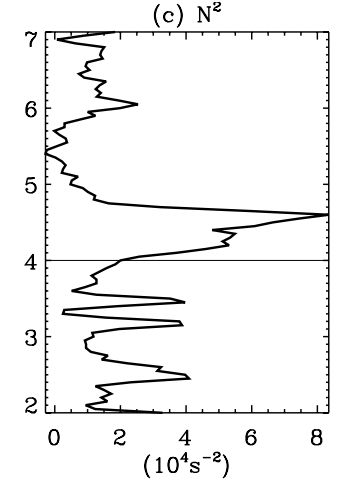

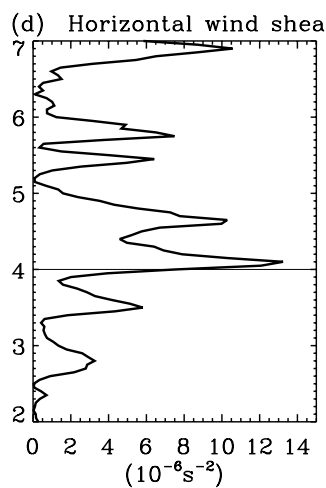

Fig. 3. Profiles of (a) temperature, (b) horizontal wind, (c) buoyancy frequency square $\left(N^{2}\right)$, (d) horizontal wind shear and (e) Richardson number over Brookhaven $\left(40.9^{\circ} \mathrm{N}, 72.9^{\circ} \mathrm{W}\right)$ at 12:00 UT on 15 November 2003. The horizontal lines denote the reference height of LTI. The vertical line in (e) denotes $R i=1$.

Bay $\left(44.5^{\circ} \mathrm{N}, 88.1^{\circ} \mathrm{W}\right)$ and Brookhaven $\left(40.9^{\circ} \mathrm{N}, 72.9^{\circ} \mathrm{W}\right)$ are all positive, which are $0.59,0.31,0.45$, and 0.49 , respectively. Considering the correlation coefficients are calculated over a long term of 10 years, these positive correlation coefficients may also indicate the relationship between horizontal wind shear and LTI.

On the whole, the monthly occurrence rates of LTI over these 4 stations have similar seasonal variations. The minimum of monthly occurrence rate over Brookhaven occurred in August 2003, around 4\%, while LTIs over the other 3 stations are not observed at all in some summer months. The maximum of the monthly occurrence rate over these 4 stations was about $31 \%$ which occurred over Brookhaven in February 2001. This maximum is not the highest value among these 56 stations. At Detroit, Michigan $\left(42.7^{\circ} \mathrm{N}\right.$, $83.5^{\circ} \mathrm{W}$ ) the maximum occurrence rate of LTI reached $36 \%$ in December, 2000; and at Buffalo, New York $\left(42.9^{\circ} \mathrm{N}\right.$, $78.7^{\circ} \mathrm{W}$ ) the maximum was $38 \%$ in January 2004 . At the other stations, the maxima have never exceeded $31 \%$. Generally, the maximum occurrence rate of LTI always occurs in winter, which may imply a close relationship between LTI and tropospheric dynamics, such as strong tropospheric jet and intensive wave activity in winter, and the minimum usually exists in summer. This feature is consistent with the results presented by Nodzu et al. (2006). Moreover, those stations over where the maximum monthly LTI occurrence rate exceeding $30 \%$ generally locate around $40^{\circ} \mathrm{N}$ and in the longitude range of $\left(70^{\circ} \mathrm{W}, 83.5^{\circ} \mathrm{W}\right)$, which is the eastern part of these stations.

Figure 5 gives the averaged monthly variations of the occurrence rate $(\%)$, base height $(\mathrm{km}$ a.m.s.l.), thickness $(100 \mathrm{~m})$, and temperature jump (K) for lower tropospheric inversions over 4 stations in 1998-2007. These characteristics of LTI all have obviously seasonal variations, especially for Green Bay, Wisconsin and Brookhaven, New York. Since monthly averaged occurrence rate of LTI over Oakland International Airport, California and Albuquerque, New Mexico are much smaller in spring and summer, the results of LTI base height, thickness and temperature jump in these two seasons may have lower reliability. The results of monthly averaged occurrence rate, not only seasonal variations but also longitudinal variations, are consistent with Fig. 4, the 

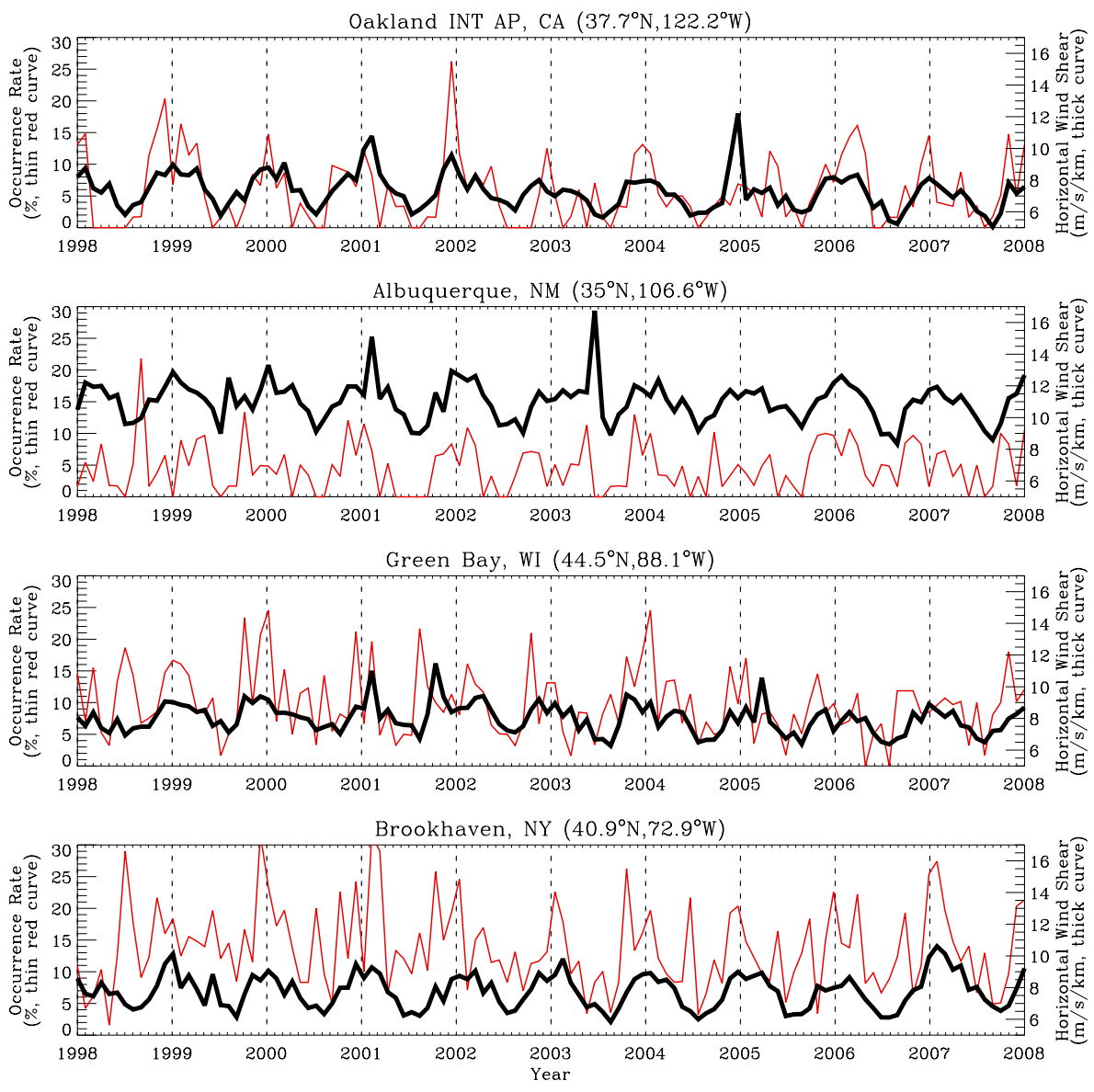

Fig. 4. Time series of the monthly occurrence rate of the lower tropospheric inversion (thin red curve) and mean horizontal wind shear in the range of 2-5 km (thick curve) over 4 stations in 1998-2007.

east stations and in winter season both with larger LTI occurrence rates. The variation of the base height over these 4 stations shows that station with higher elevation usually gets a higher LTI base height. For example, for Albuquerque, New Mexico, its elevation is the highest among these 4 stations and the minimum base height is as large as $4.8 \mathrm{~km}$ a.m.s.1., while for the other 3 stations, the elevations are much lower and the mean base heights are no larger than $3.5 \mathrm{~km}$ a.m.s.l. Both thickness and temperature jump of the LTI over all 4 stations show a clear seasonal variation, with larger values in winter and smaller values in summer. The mean thickness of 4 stations is almost the same, around $450 \mathrm{~m}$. For the temperature jump, the minimum over these 4 stations is about $1.7 \mathrm{~K}$ and the mean value for all 4 stations is around $2.0 \mathrm{~K}$.

\subsection{Longitudinal variability}

In order to investigate longitudinal variability of LTI, mean values of these structure parameters (including occurrence rate, base height) are obtained by a meridionally average of the values over stations within a $2^{\circ}$ longitude bin. As shown in Fig. 6, illustrating the averaged latitude of each longitudi- nal bin, there are three longitudinal gaps with no stations, $74^{\circ} \mathrm{W}-76^{\circ} \mathrm{W}, 112^{\circ} \mathrm{W}-114^{\circ} \mathrm{W}$ and $120^{\circ} \mathrm{W}-122^{\circ} \mathrm{W}$. Since latitude differences between two adjacent stations of these three longitudinal bin gaps are small, less than $4^{\circ}$, mean values at these three bin gaps are calculated by a linear interpolation of adjacent values. Moreover, the largest averaged latitude difference in the whole longitudinal region is just around $10^{\circ}$ (shown in Fig. 6). In the longitudinal bins of $96^{\circ} \mathrm{W}-98^{\circ} \mathrm{W}$ and $86^{\circ} \mathrm{W}-88^{\circ} \mathrm{W}$, latitude differences between the adjacent bins are very large, while comparing with the characteristics of LTI in these two longitudinal bins, the differences are not obvious. This suggests that the possible latitudinal variations contribute little to longitudinal variation of LTIs in the geographical coverage considered in this paper.

Figure 7 demonstrates the longitudinal variation of the meridionally averaged occurrence rate, base height, thickness, temperature jump of the LTI over 56 stations during the whole 10 years. It is interesting that we can divide the contiguous United States (56 stations) into two regions according to their altitudes and longitudes. The vertical lines in Fig. 7 separate these two regions. One is 

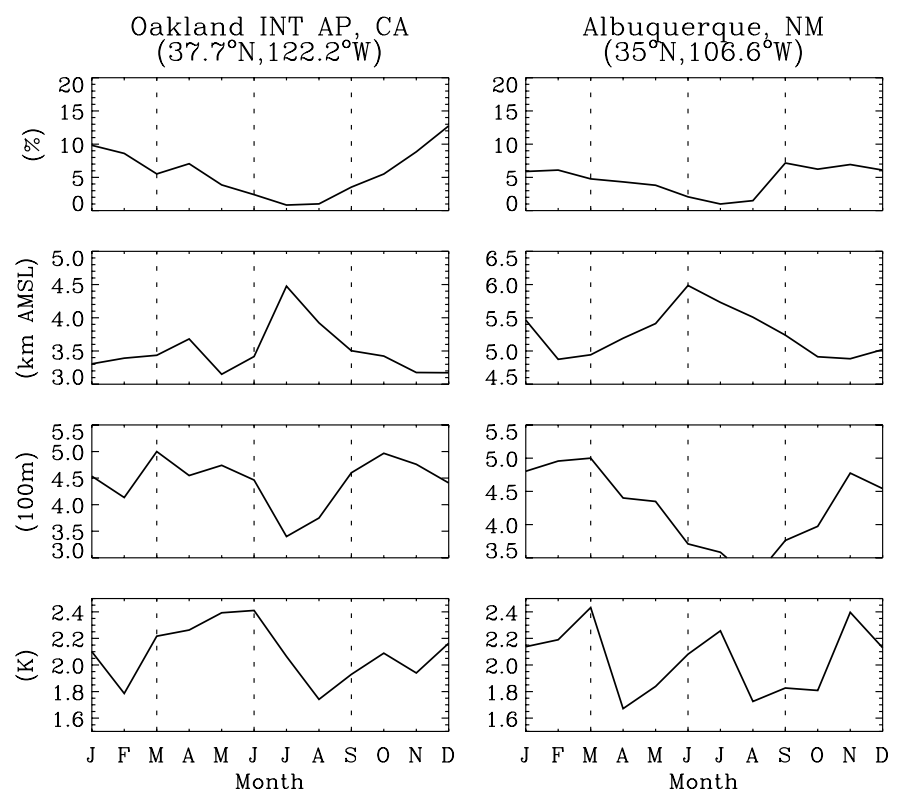
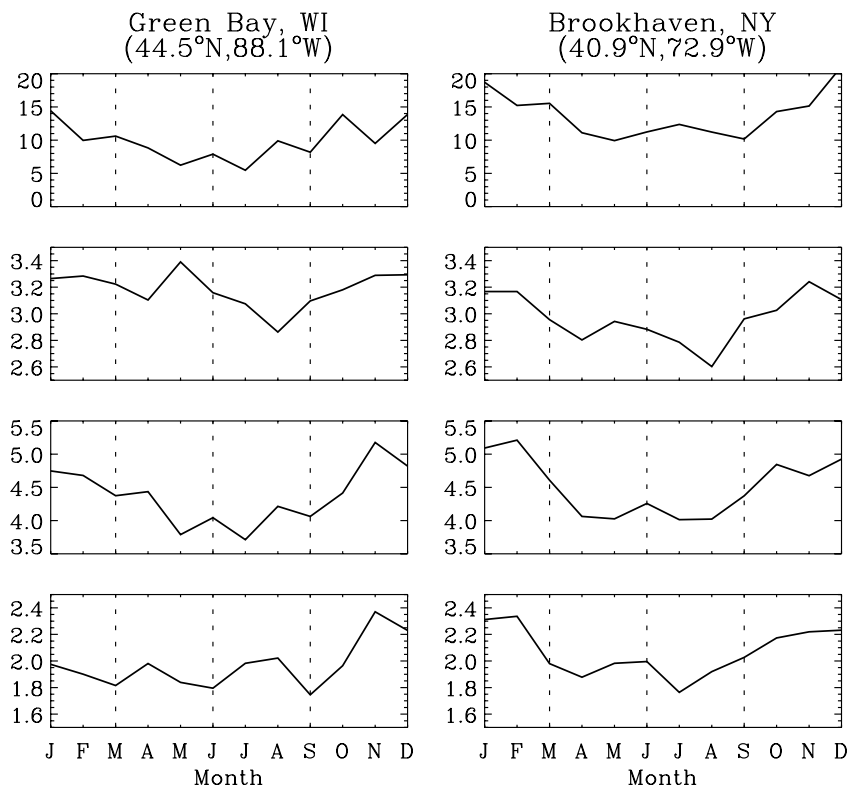

Fig. 5. Averaged monthly variations of the occurrence rate (\%), base height (km a.m.s.l.), thickness (100 m) and temperature jump (K) for lower tropospheric inversions over 4 stations in 1998-2007.

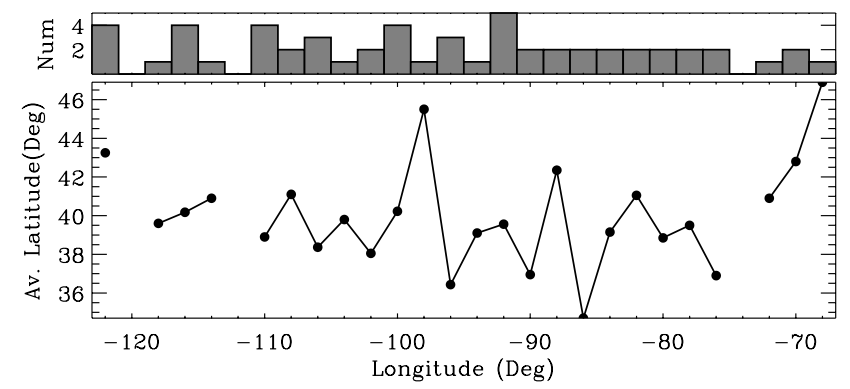

Fig. 6. Averaged latitude of each longitude bin (lower panel) and the station numbers in each bin (upper panel).

$68^{\circ} \mathrm{W}-100^{\circ} \mathrm{W}$, which have lower elevations, generally less than $500 \mathrm{~m}$; the other is $100^{\circ} \mathrm{W}-122^{\circ} \mathrm{W}$, which have higher elevations, mostly exceeded $1000 \mathrm{~m}$. The most prominent result in Fig. 7 is the apparent longitudinal variation of LTI occurrence rate. From the overall trend, the LTI occurrence rate shows an obvious west to east increasing trend, which has never been reported before. In the $100^{\circ} \mathrm{W}-122^{\circ} \mathrm{W}$ region, all the mean occurrence rates are less than $7 \%$, with the minimum of about $3.7 \%$ at a longitude around $104^{\circ} \mathrm{W}$; in the $68^{\circ} \mathrm{W}-100^{\circ} \mathrm{W}$ region, the occurrence rate is much larger and increases eastward, with the maximum of about $14.5 \%$ at a longitude around $72^{\circ} \mathrm{W}$. Such a prominent longitude dependence of the occurrence rate may be closely connected with the formation mechanisms of LTIs.

The longitudinal variation of LTI base heights is opposite to that of the occurrence rate. The base heights of LTI mostly locate between 3.0 and $5.0 \mathrm{~km}$ a.m.s.l. It is clear that sta- tions with a higher altitude usually have higher base heights and lower occurrence rates. This is different from the results presented by Nodzu et al. (2006), which suggested that the height of the stable layer did not depend on the elevation of the underlying topography over low-latitude stations in the Indochina Peninsula region. The longitudinal variations of thickness and temperature jump of LTI are not as obvious as the occurrence rate. The meridionally averaged thickness and temperature jump vary in rather small ranges, which are $420-465 \mathrm{~m}$ and $1.9-2.2 \mathrm{~K}$, respectively.

To better understand the basic features of LTI, especially the longitudinal variation of LTI occurrence rates, we analyse individually longitudinal variation of LTIs in 4 different seasons. Figure 8 displays longitudinal variations of meridionally averaged occurrence rate of LTI (black curve) and mean horizontal wind shear (red curve) in winter (December, January and February), spring (March, April and May), summer (June, July and August) and autumn (September, October and November). Generally, LTI occurrence rate (black curve) is the highest and lowest in winter and summer, respectively; the occurrence rate in autumn is larger than that in spring. In different seasons, the maxima of occurrence rate almost occur in the same longitude bin of $72^{\circ} \mathrm{W}$, except that in autumn the maximum occurs around $68^{\circ} \mathrm{W}$. If we took $100^{\circ} \mathrm{W}$ as a borderline, it is apparent that occurrence rates in the region of $100^{\circ} \mathrm{W}-122^{\circ} \mathrm{W}$ are much smaller than those in $68^{\circ} \mathrm{W}-100^{\circ} \mathrm{W}$. More importantly, longitudinal variations of LTI occurrence rate in 4 different seasons are quite consistent. Not only in the largest occurrence rate season (winter), but also in the smallest occurrence rate season (summer), LTI occurrence rates show an obvious eastward increasing trend. 

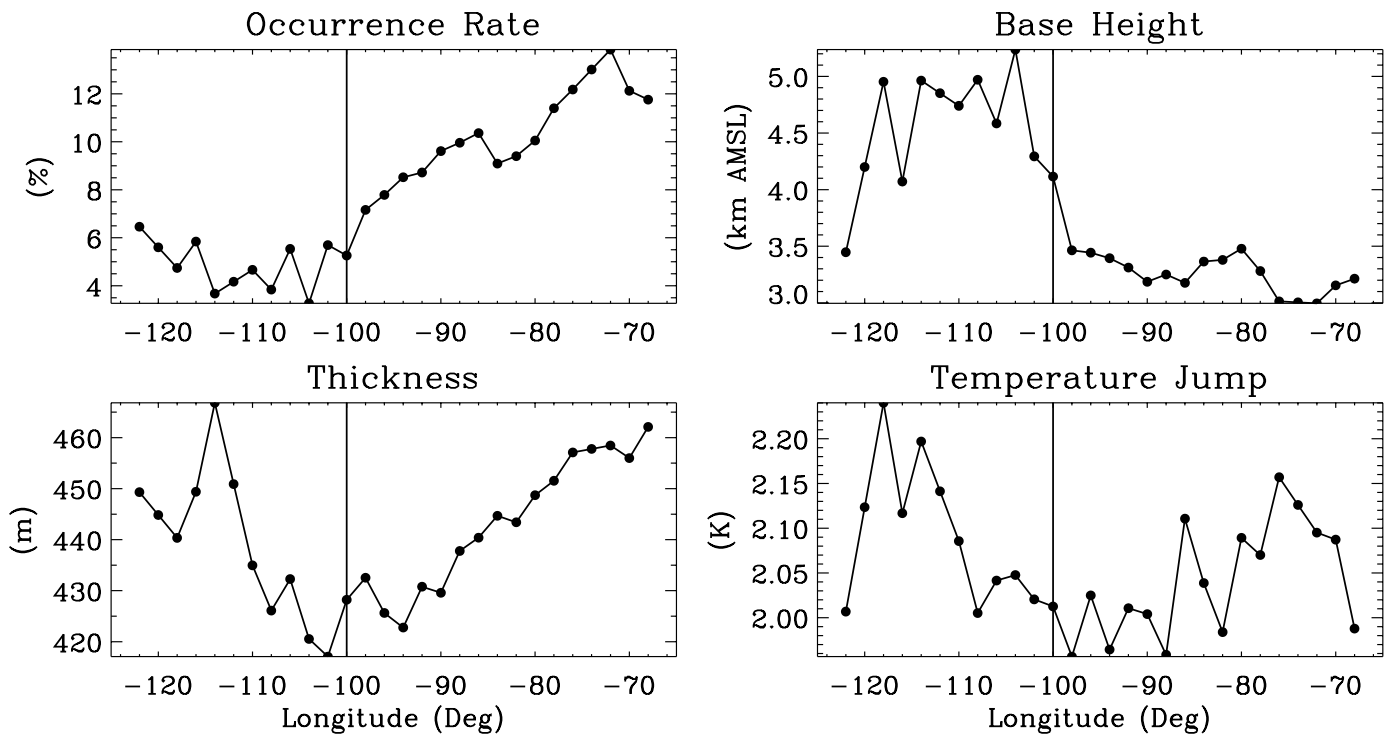

Fig. 7. Longitudinal variation of meridionally averaged occurrence rate, base height, thickness, temperature jump of lower tropospheric inversions over 56 stations in 1998-2007.
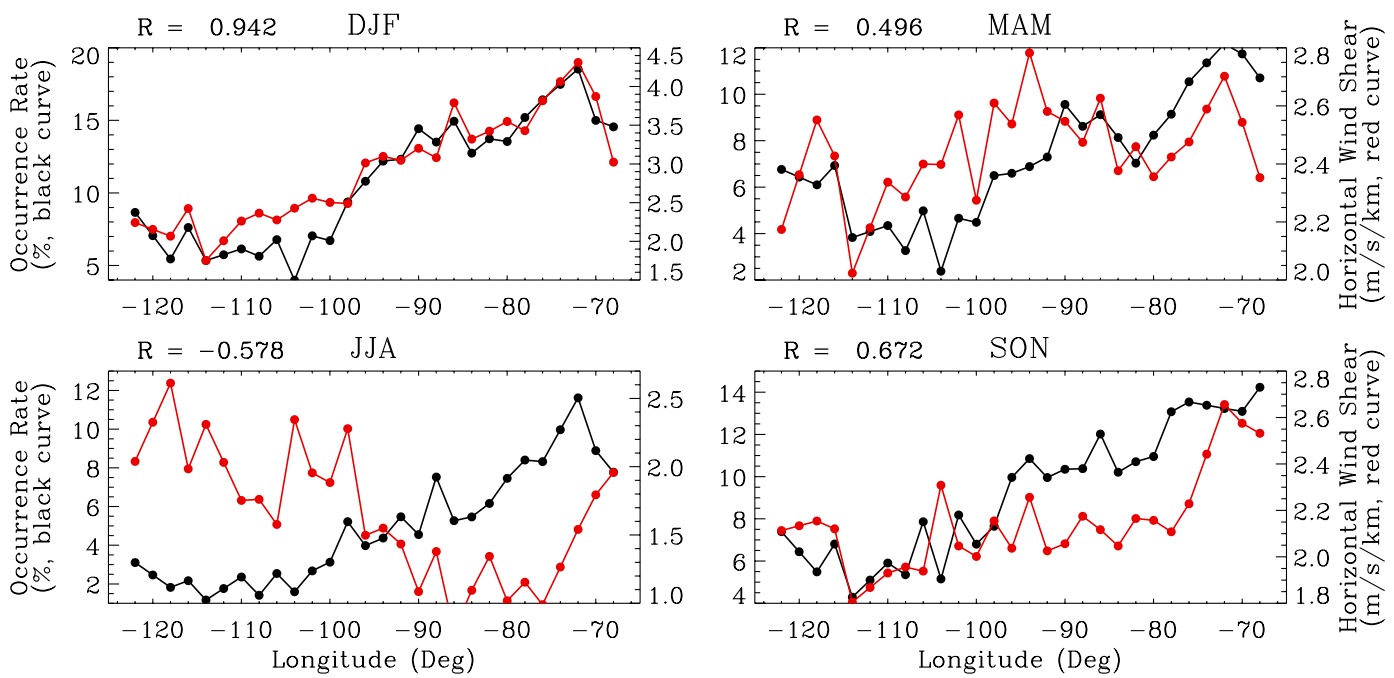

Fig. 8. Longitudinal variation of meridionally averaged occurrence rate of lower tropospheric inversions (black curve) and mean horizontal wind shear in the range of $2-5 \mathrm{~km}$ (red curve) over 56 stations in different seasons.

In spring and autumn, the longitudinal variations also have similar tendency. These indicate that this prominent longitudinal variation of mean occurrence rate of LTI averaged over all seasons, as shown in Fig. 7a, does exist in every season instead of just reflecting the longitudinal variation in winter when the occurrence rate is much higher.

By analysing two LTI events, Zhang et al. (2009) found that both the inversion layers are closely related with the intensive inertial gravity waves propagating in a winter tropospheric jets. Especially in the duration of LTI1, most of the gravity waves propagated upward and along the background wind, implying they may encounter the critical layer due to the Doppler shifting of the strong troposphere jet in winter, and finally these gravity waves were captured by the background wind field. On the other hand, in the early stage of LTI1, the gravity wave horizontal wind amplitudes were very large and exceeded the intrinsic horizontal phase velocities, which led to convective instability and intensive turbulence. Subsequently, the gravity waves' induced intensive turbulence may yield a downward energy transport. Thus, the gravity wave energies, restricted by the tropospheric jet, were transported downward to the lower troposphere and finally formed LTI1. A similar mechanism has been proposed to account for the mesosphere inversion layer (MIL) (Liu and Meriwether, 2004; Lehmacher et al., 2006). Moreover, some quantitative analyses by Lehmacher et al. (2006) and Zhang 

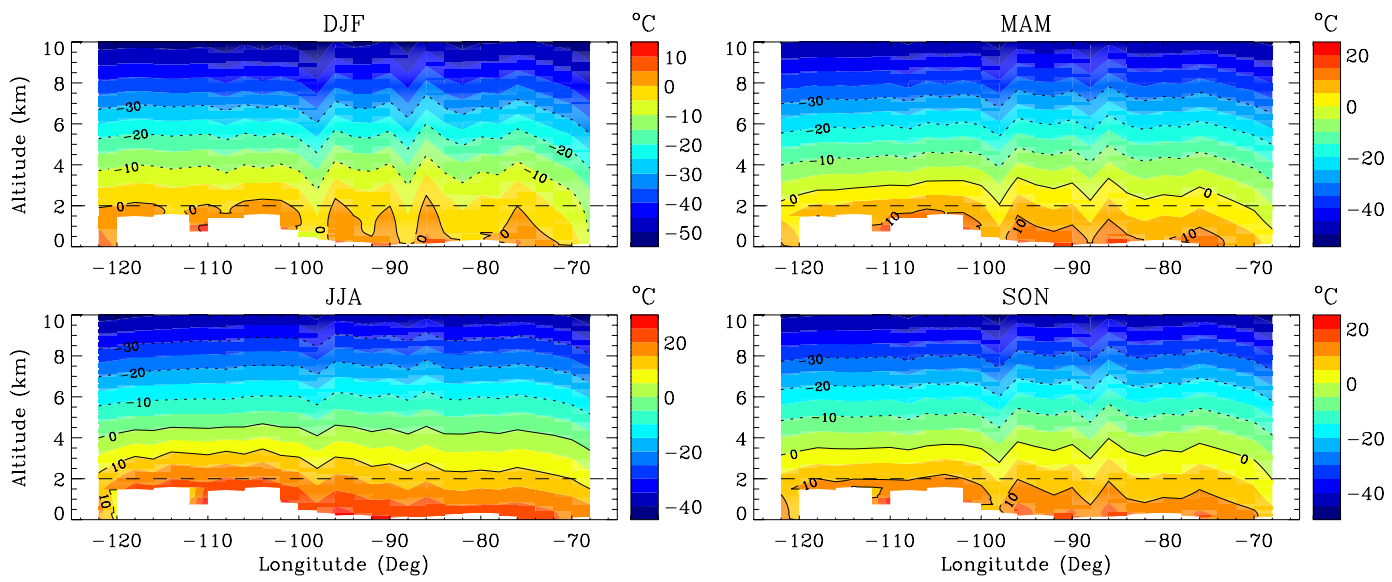

Fig. 9. Longitude-altitude distributions of the meridionally averaged temperature over 56 stations in different seasons.

et al. (2009) have confirmed that the observed turbulent heating rate and erosion timescale of inversions were rather close to the theoretical estimations.

Considering that tropospheric jet is one of the most remarkable dynamical characteristics in the lower atmosphere at mid-latitude in winter and it usually induces strong wind shear which may yield instability or even intensive turbulence, we first analyse the background horizontal wind shear. Then we calculate the mean horizontal wind shear averaged over the height coverage from 2 to $5 \mathrm{~km}$ a.g.l. as introduced in Sect. 3.1. In looking at longitudinal variations of mean horizontal wind shear (red curve) in Fig. 8, the trends in winter, spring and autumn are extraordinarily consistent with that of LTI occurrence rates. From west to east, the horizontal wind shear exhibits an obvious increase tendency. In the larger LTI occurrence rate region $\left(68^{\circ} \mathrm{W}-100^{\circ} \mathrm{W}\right)$ in winter, all the values of wind shear exceed $2.5 \times 10^{-3} \mathrm{~s}^{-1}$, whereas in the smaller LTI occurrence rate region $\left(100^{\circ} \mathrm{W}-122^{\circ} \mathrm{W}\right)$, the values do not reach $2.5 \times 10^{-3} \mathrm{~s}^{-1}$. It is interesting that in winter and autumn, the maxima of mean horizontal wind shear, exceeding $4.3 \times 10^{-3} \mathrm{~s}^{-1}$ and $2.6 \times 10^{-3} \mathrm{~s}^{-1}$, occur in the longitude bin of $72^{\circ} \mathrm{W}$ where LTI occurrence rate reaches its maximum. Moreover, it is worthwhile to note that the correlation coefficients between LTI occurrence rate and mean horizontal wind in winter is extremely high, 0.94 . The correlation coefficients in autumn and spring are 0.67 and 0.50 , respectively. It implies that the prominent longitudinal variation of LTI occurrence rate in winter, spring and autumn is closely linked with strong horizontal wind shear. LTI in these three seasons may originate from dynamical instability induced by strong wind shear. However, in summer the horizontal wind shear is rather small and from west to east the horizontal wind shear exhibits an evident decrease tendency. The longitudinal variation of the horizontal wind shear in summer seems to have an opposite trend to that of the LTI occurrence rate and their correlation coefficient is -0.58 . The negative correlation coefficient in summer, indicating longi- tudinal variation of LTI occurrence rate in summer, cannot be explained solely by the horizontal wind shear and there should have been other causes responsible for LTIs.

In order to investigate the prominent longitudinal variation of LTI occurrence rate in summer, we consider the geography and the climatology of the contiguous United States compositively. The west part of the contiguous United States is mountain region where elevations are much higher than those in the east part. In the troposphere, the temperature generally decreases with increasing height relative to the ground. That is to say, for the same height a.m.s.l., especially for heights below $5 \mathrm{~km}$ a.m.s.l., the temperature in the western United States may be higher than in the eastern region. This horizontal difference in temperature may easily form a front layer.

Figure 9 gives the longitude-altitude distributions of the meridionally averaged temperature over 56 stations in different seasons. The altitude here is the height a.m.s.l. and the blanks in Fig. 9 indicate the averaged elevation heights of each longitude bin. The horizontal dash lines denote $2 \mathrm{~km}$ a.m.s.l. Focusing on the height range of $2-4 \mathrm{~km}$ a.m.s.l. in Fig. 9, we can observe that at the same specific sea level height, temperatures in the smaller LTI occurrence rate region $\left(100^{\circ} \mathrm{W}-122^{\circ} \mathrm{W}\right)$ is much higher than those in the larger LTI occurrence rate region $\left(68^{\circ} \mathrm{W}-100^{\circ} \mathrm{W}\right)$ in summer. For instance, in summer, at the height of $3 \mathrm{~km}$ a.m.s.l., temperatures in the west part of the continental United States is generally $2-3 \mathrm{~K}$ higher than those in the east part at the height of $3 \mathrm{~km}$ a.m.s.l. This temperature difference is close to the mean LTI temperature jump. While in other seasons the difference in temperature between these two regions is much smaller. Although in the present work, we don't present the longitude-altitude distributions of temperature for a certain measurement, the statistical result (Fig. 9) does exhibit an obvious horizontal temperature gradient in the continental United States at the heights of $2-4 \mathrm{~km}$ a.m.s.l. in summer, which is quite consistent with the result presented by Keyser and Shapiro (1986), in which the longitude-altitude 
distribution of temperature for a single measurement was presented. Generally, our statistical results indicate that in summer, at the absence of strong wind shear, the frontal system is quite prevailing, which may cause LTI in summer.

The above discussion on horizontal difference in temperature alone can explain the occurrence inversions in summer, but cannot explain the longitudinal variation of LTI in this season. Here, we analysed the background horizontal wind structure of these 56 stations (not shown) and found that the meridionally averaged zonal winds are mostly eastward in all 4 seasons from 2 to $7 \mathrm{~km}$ a.g.l. This means the inversion may be formed more frequently in the eastern region $\left(68^{\circ} \mathrm{W}-100^{\circ} \mathrm{W}\right)$ due to the horizontal wind advection process. It does not mean that one specific air parcel in the western region moves thousands of kilometres to the eastern region without temperature changes and then forms a LTI in the eastern region, but implies that it is easier and has much higher possibility for the air parcels with higher temperature in the westside moving to the eastside and forming an inversion. Hence, the combination effects of the horizontal difference in temperature and horizontal wind cause the obvious eastward increasing trend of occurrence rate of LTI in summer. On the other hand, although much larger horizontal wind occurs in winter, spring and autumn, the frontal systems are very weak due to the small horizontal gradients of temperature, leading to small contributions of the frontal system to LTI in these seasons. Therefore, we speculate that LTI in summer is probably induced mainly by frontal system.

\section{Conclusions}

Ten years (1998-2007) high vertical resolution radiosonde observations over 56 United States stations are analysed to derive the statistical characteristics (including seasonal, annual, inter-annual and geographical variability) of the basic structure parameters of LTIs. It is found that LTI between 2 and $7 \mathrm{~km}$ a.g.1. is a common feature over the continental United States. Throughout the whole 10 years, the averaged occurrence rates of LTI vary from $3.7 \%$ to $14.5 \%$; the averaged base heights relative to the ground of LTI are in the range of 3-5 km a.m.s.l.; the averaged thicknesses and temperature jump variation ranges are 420-465 $\mathrm{m}$ and 1.9$2.2 \mathrm{~K}$, respectively. These parameters have an obvious seasonal variation. In winter, the occurrence rate, thickness and temperature jump of LTIs all have much larger values than those in summer.

From geographical distribution of the structure parameters of LTI, the most prominent result is that LTI occurrence rate shows an obvious west-east increasing trend in all 4 seasons. To the best of our knowledge, this is the first time this prominent longitude variation is documented.

By analysing seasonal and longitudinal variations of the horizontal wind shear and the cross-sections of meridionally averaged temperature in the lower atmosphere over 56 stations in different seasons, we find that LTIs are probably formed jointly by strong horizontal wind shear and frontal system. Although both mechanisms (horizontal wind shear and frontal system) exist throughout the whole year over the continental United States, horizontal wind shear is dominant in winter, spring and autumn as a result of strong tropospheric jet in these seasons in the lower atmosphere, while the frontal system is strong in summer owing to the large horizontal gradients of temperature. Considering that the horizontal wind shear, LTI occurrence rate, LTI temperature jump and LTI thickness, are much larger in winter, we conclude that the background horizontal wind shear contributes more to the formation of LTI than the frontal system does.

Zhang et al. (2009) investigated two LTI events by analysing 3-hourly radiosonde observations in January 2007 and found that strong wind shear in winter induced by intensive turbulence may yield a downward energy transport and finally form these two inversions. And from the quantitative analyses, they found that the observed turbulent heating rate and erosion timescale are close to the theoretical estimations. The data used in this paper are from routine radiosonde observations with a large time interval, $12 \mathrm{~h}$. Considering inversions generally last only several days, therefore, it is difficult to present the detailed evolution of LTI and estimate the energy flux quantitatively. However, we want to note that the presented extreme consistencies of seasonal and longitudinal variations among horizontal wind shear and LTI occurrence rate are based on statistical results from plentiful measurements. Thus, we believe these statistic results will help us to understand LTI better.

Acknowledgements. This work was jointly supported by the National Natural Science Foundation of China through grant 40825013, 40731055 and 40974082; the Ocean Public Welfare Scientific Research Project, State Oceanic Administration People's Republic of China (No. 201005017), the China Meteorological Administration Grant (GYHY201106011) and the Open Programmes of State Key Laboratory of Space Weather.

Topical Editor P. Drobinski thanks one anonymous referee for her/his help in evaluating this paper.

\section{References}

Augstein, E., Schmidt, H., and Ostapoff, F.: The vertical structure of the atmospheric planetary boundary layer in undisturbed trade winds over the Atlantic Ocean, Bound.-Lay. Meteorol., 6, 129150, 1974.

Birner, T., Sankey, D., and Shepherd, T. G.: The tropopause inversion layer in models and analyses, Geophys. Res. Lett., 33, L14804, doi:10.1029/2006GL026549, 2006.

Busch, N., Ebel, U., Kraus, H., and Schaller, E.: The structure of the subpolar inversion- capped ABL, Arch. Meteor. Geophy., 331, 1-18, 1982.

Chen, Y. -L.: Final Report of Project: Characteristics of Trade-wind Inversion over the Hawaiian Islands, University of Hawaii, Honolulu, 2006. 
Fujiwara, M., Xie, S.-P., Shiotani, M., Hashizume, H., Hasebe, F., Vömel, S. J., Oltmans, H., and Watanabe, T.: Uppertropospheric inversion and easterly jet in the tropics. J. Geophys. Res., 108(D24), 2796, doi:10.1029/2003JD003928, 2003.

Glickman, T.: Glossary of Meteorology, 2nd ed., American Meteorological Society, 855 pp., 2000.

Hashizume, H., Xie, S.-P., Fujiwara, M., Shiotani, M., Watanabe, T., Tanimoto, Y., Liu, W. T., and Takeuchi, K.: Direct observations of atmospheric boundary layer response to SST variations associated with tropical instability waves over the eastern equatorial Pacific, J. Climate, 15, 3379-3393, 2002.

Hoinka, K. P.: Temperature, humidity, and wind at the global tropopause, Mon. Weather Rev., 127, 2248-2265, 1999.

Johnson, R. H., Rickenbach, T. M., Rutledge, S. A., Ciesielski, P. E., and Schubert, W. H.: Trimodal characteristics of tropical convection, J. Climate, 12, 2397-2418, 1999.

Kahl, J. D., Serreze, M. C., and Schnell, R. C.: Tropospheric low-level temperature inversions in the Canadian arctic, Atmos.Ocean, 30, 511-529, 1992.

Kay, J. E. and Gettelman, A.: Cloud influence on and response to seasonal Arctic sea ice loss, J. Geophys. Res., 114, D18204, doi:10.1029/2009JD011773, 2009.

Keyser, D. and Shapiro, M. A.: A review of the structure and dynamics of upper-level frontal zones, Mon. Weather Rev., 114, 452-499, 1986.

Lehmacher, G. A., Croskey, C. L., Mitchell, J. D., Friedrich, M., Lübken, F.-J., Rapp, M., Kudeki, E., and Fritts, D. C.: Intense turbulence observed above a mesospheric temperature inversion at equatorial latitude, Geopgys. Res. Lett., 33, L08808, doi:10.1029/2005GL024345, 2006.
Liu, H.-L. and Meriwether, J. W.: Analysis of a temperature inversion event in the lower mesosphere, J. Geophys. Res., 109, D02S07, doi:10.1029/2002JD003026, 2004.

Liu, Y. and Key, J.: Detection and analysis of clear sky, lowlevel atmospheric temperature inversions with MODIS, J. Atmos. Oceanic Technol., 20, 1727-1737, 2003.

Nielsen, J. W. and Neilley, P. P.: The vertical structure of New England coastal fronts, Mon. Weather Rev., 118, 1793-1807, 1990.

Nodzu, M. I., Ogino, S.-Y., Tachibana, Y., and Yamanaka, M. D.: Climatological description of seasonal variations in lowertropospheric temperature inversion layers over the Indochina Peninsula, J. Climate, 19, 3307-3319, 2006.

Palmén, E. and Newton, C. W.: Atmospheric circulation systems: Their structure and physical interpretation. New York USA: Academic Press, 281-286, 1969.

Paul, Y. H.: Inversions over the tropical eastern Pacific Ocean, Mon. Weather Rev., 96, 177-185, 1968.

Thomas, S.: Cloud Forests in the Humid Tropics. The United Nations University, Tokyo, Japan: United Nations University Press, 1987.

Zhang, Y. H., Zhang, S. D., and Yi, F.: Characteristics of trade wind inversion over the Gulf of Mexico Coastlands of the United States from radiosonde observation, Sci. Tech. Rev. (Chinese), 25(8), 19-25, 2007.

Zhang, Y. H., Zhang, S. D., and Yi, F.: Intensive radiosonde observations of lower tropospheric inversion layers over Yichang, China, J. Atmos. Solar-Terr. Phys., 71, 180-190, 2009. 